\title{
Navegações, descobertas, encontros e reencontros na poesia de Sophia de Mello Breyner Andresen
}

\author{
La Salette Loureiro
}

\author{
The world is wide and yet it is like a home. \\ (Georg Lukács) \\ O maré o caminho para a minha casa. \\ (Sophia de Mello Breyner Andresen)
}

\section{O Universo poético de Sophia}

Sophia de Mello Breyner Andresen (Porto, 6/11/1919 - Lisboa, 2/7/2004) é uma das mais reputadas escritoras portuguesas do século XX. Para além de escritora, ela destacou-se também pela sua acção cívica contra a ditadura de Salazar, nomeadamente fazendo parte do grupo de Católicos Progressistas, um grupo particularmente marcado pelas doutrinas personalista e existencialista e pelo pensamento do cientista católico Teilhard de Chardin (cfr. Andresen 2015, 894).

O seu primeiro livro, intitulado Poesia, foi publicado em $1944 \mathrm{e}$ a partir dessa data a autora publicou uma vasta obra, que inclui poesia, narrativa, teatro, ensaio e tradução, abordando uma série de temas que se tornam recorrentes. A caracterização da sua poesia é feita pela própria, quando diz «sempre a poesia foi para mim uma perseguição do real» (Andresen 2015, 893), sendo que «o real é aquilo que emerge e se manifesta $\gg$ (cfr. Andresen 1985, 3).

Na poesia de Sophia, destaca-se a interacção constante do sujeito poético com os quatro elementos primordiais (terra, água, ar e fogo), com a predominância da água, que se manifesta sobretudo através do tema do mar.

Em nosso entender, para além de uma busca da imanência, a presença avassaladora do espaço físico na poesia da autora e a frequência com que o sujeito poético interage e se identifica com ele configuram uma situação de «pensée-

La Salette Loureiro Cham, FCSH, Universidade Nova de Lisboa, Lisboa, Portugal, Isloureiro@sapo.pt, 0000-0001-9236-2735

FUP Best Practice in Scholarly Publishing (DOI 10.36253/fup_best_practice)

La Salette Loureiro, Navegações, descobertas, encontros e reencontros na poesia de Sophia de Mello Breyner Andresen, pp. 295-317, (c) 2021 Author(s), CC BY 4.0 International, DOI 10.36253/978-88-5518467-0.24, in Michela Graziani, Lapo Casetti, Salomé Vuelta García (edited by), Nel segno di Magellano tra terra e cielo. II viaggio nelle arti umanistiche e scientifiche di lingua portoghese e di altre culture europee in un'ottica interculturale, ( 2021 Author(s), content CC BY 4.0 International, metadata CC0 1.0 Universal, published by Firenze University Press (www.fupress.com), ISSN 2704-5919 (online), ISBN 978-88-5518467-0 (PDF), DOI 10.36253/978-88-5518-467-0 
-paysage», como proposto por Michel Collot. Segundo este autor, «le monde comme tel n'existe que pour une conscience qui ne se sait elle-même qu'en se projectant vers lui $\gg$ (Collot 2011,33), considerando que «l'espacement du sujet est ce mouvement par lequel il quitte son identité close sur elle-même pour s'ouvrir au dehors, au monde et à l'autre» (Collot 2011, 34).

Por outro lado, os contrastes que esta poesia estabelece entre tipos de espaço convocam a dicotomia espaces lisses/ espaces striées, estabelecida por Deleuze e Guattari. Seguramente, a abordagem do espaço pela autora enquadra-se nos conceitos de espace vécu, de Henri Lefèbvre, e de thirdspace, de Edward Soja.

Conjuntamente com a natureza e todo o mundo exterior, nesta poesia há valores permanentemente perseguidos, que se manifestam sobretudo pela sua ausência e por serem objecto de busca. São eles a verdade, a liberdade, a harmonia, a unidade, a inteireza, a perfeição, a justiça, a transparência, a forma justa, entre outros.

Na verdade, a busca desses valores revela a fractura e a ferida aberta pela separação entre deuses, homens, natureza e cosmos, como se constata nos poemas Os gregos (Andresen 2015, 635) e O Rei de Itaca ${ }^{1}$ (Andresen 2015, 681), a perda da unidade que existia na Grécia antiga e entretanto se perdeu, sobretudo na sociedade ocidental (cfr. Andresen 1967, 9) ${ }^{2}$.

A poesia de Sophia mostra a destruição dessa unidade inicial e a tentativa de recuperação desse espaço-tempo, ainda que de forma provisória e temporária, por exemplo, através de ritos, como se vê em vários poemas, como é o caso de Os gregos, onde se diz «por isso repetíamos os gestos rituais que restabelecem / o estar-ser-inteiro inicial das coisas $\gg$ (Andresen 2015, 635), ou em Inicial:

O mar azul e branco e as luzidias

Pedras - O arfado espaço

Onde o que está lavado se relava

Para o rito do espanto e do começo

Onde sou a mim mesma devolvida

Em sal espuma e concha regressada

À praia inicial da minha vida (Andresen 2015, 615).

Esta busca opera tanto a nível individual como colectivo, estando em causa a procura do Ser e a redenção da Humanidade, que poeticamente se exprime tanto directa como simbolicamente.

Neste enquadramento, expulso do paraíso, situado e condicionado, o sujeito poético de Sophia vive a experiência de se sentir fora de casa, desenraizado, perdido, «living "a sense of homelessness" » (Tally 2018, 54), «the loss of a sense of "home" (Tally 2018, 156), «the feeling of being lost» (Tally 2018,

1 «A civilização em que estamos é tão errada que/ Nela o pensamento se desligou da mão» (Andresen 2015, 681).

2 Vários pensadores do século XX sublinham também a ruptura entre o Homem e a Natureza, como é o caso de Edgar Morin (cfr. Collot 2011, 54-5). 
119), uma situação «evoking an anxiety that Martin Heidegger had associated directly with the uncanny, the unheimlich or "unhomely", the Nicht-zu-hausesein ("not-being-at-home")» (Tally 2018, 156).

Esta situação do sujeito poético, típica do existencialismo, é análoga à dos descobridores que navegavam sem mapa (cfr. Andresen 2015, 728), ou à do poeta que, qual navegador (cfr. Andresen 1985, 3), tem de arrancar o poema ao caos e transformá-lo em cosmos, construindo «o fio de linho da palavra» (Andresen 2015, 629) que o salvará da perdição no labirinto, porque, para a autora, «a palavra é uma forma de não se ser devorado pelo caos» (cfr. Andresen 1985, 3) e a necessidade da escrita decorre de «uma sensação de perdição que nos leva a escrever, até para ver onde estamos, para compreender onde estamos» (cfr. Andresen 1982, 4).

Assim, a tarefa dos escritores e a dos descobridores, tal como perspectivado no poema Mundo nomeado ou descoberta das ilhas (Andresen 2015, 500), é semelhante à do cartógrafo, porque «the cartographer organizes the elements and colours of the map to make things intelligible, familiar, and generally known to the viewer» (Tally 2018, 131).

Em nosso entender, globalmente, poder-se-á esquematizar o universo poético de Sophia, adaptando a todos os aspectos da sua poesia a proposta feita por Emanuel Guerreiro (Guerreiro 2013, 59) relativa a uma perspectiva bucólica. Assim, nesta reformulação, ficaríamos com um conjunto composto por tese, antítese, síntese, em que:

- tese é a visão/ nostalgia de um espaço-tempo perfeito ocorrido num passado longínquo, onde e quando ainda existia a unidade do Ser e a aliança entre o Homem, Deus, ou deuses, e o Universo ainda não tinha sido quebrada;

- antítese é a denúncia de um espaço-tempo (aqui-agora) degradado, de separação e incompletude ${ }^{3}$;

- síntese é o projecto / a construção ideal(izada) de um espaço-tempo que recupere a unidade e a perfeição perdidas, a verdade do Ser e a aliança entre o Homem, Deus, ou deuses, e o Universo ${ }^{4}$.

Na verdade, este projecto vai sendo anunciado ao longo do tempo, mas aparece condensado num dos seus poemas, sintomaticamente intitulado Projecto II, onde se diz:

Esta foi sua empresa: reencontrar o limpo

Do dia primordial. Reencontrar a inteireza

Reencontrar o acordo livre e justo

E recomeçar cada coisa a partir do princípio

(Andresen 2015, 698).

3 «Penso sobretudo que a sociedade em que vivemos é própria de um mundo que está a acabar. Há um desastre cultural em todo o Ocidente e em Portugal esse desastre cultural conjuga-se com o "caso mental português"» (Andresen 1982, 4).

4 «Semelhante ao corpo de Orfeu dilacerado pelas Fúrias este reino está dividido. Nós procuramos reuni-lo, procuramos a sua unidade, vamos de coisa em coisa» (Andresen 2015, 890). 
De forma ainda mais sintética, a autora afirma que «é uma ambição: o regresso total ao paraíso terrestre» (Andresen 1991, 9), pois acredita que esse paraíso não está perdido e «às vezes encontra-se. $O$ que não se encontra é sob a forma de eternidade. Sub specie eternitate» (Andresen 1991, 9).

Em suma, trata-se da «busca do recomeço», como a própria autora admite em entrevista, ao afirmar que «a busca do recomeço não é melancólica, é um acto de confiança. [...] Penso que o mito do recomeço está latente na minha poesia» (Andresen 1989a, 55-57R).

Assim, apesar das sucessivas falhas na realização do seu projecto, o sujeito poético não desiste e compromete-se com uma contínua tentativa, individual e colectiva, no sentido da sua concretização, porque, mais uma vez, mesmo perante a negatividade do presente, ele sabe que existe «a praia lisa que sonhei» (Andresen 2015, 767), e deste modo continuará buscando a «pátria do ser», configurada como «um mundo mais inteiro e mais real» (Andresen 2015, 660).

Neste enquadramento, determinados espaços-tempos surgem na poesia de Sophia como heterotopias, no sentido definido por Michel Foucault, como é o caso da Grécia antiga ${ }^{5}$ e os espaços descobertos pelos navegadores portugueses dos séculos XV e XVI, que, talvez não por acaso, se dirigiram maioritariamente para Oriente, para onde as crenças do mundo medieval ocidental apontavam a localização do Jardim do Éden (cfr. Brito 1983), e onde Sophia acredita que os valores que defende ainda não foram degradados.

Como seria de esperar, o tema das navegações portuguesas do tempo dos Descobrimentos na poesia da autora enquadra-se neste projecto de recomeço, que consiste numa re-ligação horizontal e vertical, tendo como centro o Homem e a sua ligação com o Ser, o Cosmos e Deus ou os deuses (cfr. Figura 1).

\section{Projecto: Re-Ligação}

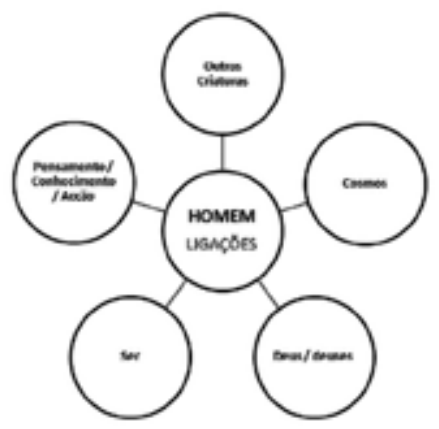

Sophia: Projecto de Re-Ligação, imagem da minha autoria.

5 «A Grécia é um ponto de partida a que justamente é preciso regressar porque então o homem tentou partir da imanência, partir do seu estar na terra» (Andresen 1982, 4). 
No fundo, estas navegações puseram em prática a ideia de Collot, segundo a qual «l'Horizon trace un trait d'union entre les trois instances qui fondent, dans la plupart des cultures, l'ordre de l'univers: la terre, l'homme et le ciel» (Collot 2011, 93-4), considerando, assim, a noção de «horizonte» à maneira de Husserl, ou seja, não como uma linha mas como uma estrutura (de horizonte), «qui régit aussi bien la perception des choses dans l'espace, que la conscience intime du temps et le rapport à autrui» (Collot 2011, 93), o que parece adaptar-se ao caso de Sophia.

A realização deste projecto inclui a Linguagem e a Poesia, no sentido que lhes é dado por Heidegger, que coincide com a poética de Sophia.

\section{Navegações}

Neste texto, pretendemos analisar os aspectos mencionados no nosso título, concentrando-nos principalmente no livro Navegações, publicado em 1983.

Neste livro, apesar de ser poesia lírica, devido à sua temática, ocorrem algumas categorias narrativas, como narração, focalização, personagens, acção, tempo e espaço, funcionando este último como elemento unificador. O conteúdo do livro centra-se nas Descobertas portuguesas dos séculos XV e XVI, um tema recorrente na obra da autora, cuja abordagem vai sempre no sentido da admiração pelos feitos realizados pelos navegadores e da nostalgia da epopeia, mas acrescentando-lhe uma visão pessoal e original, que se enquadra de forma harmónica no seu projecto ético e poético.

De facto, o livro reafirma a mundivisão da autora, inserindo-se na sua permanente busca do Ser, nos termos de Heidegger, e confirmando os valores sempre perseguidos, desenhando, assim, um mundo possível, onde a Humanidade atingiria um elevado grau de união e perfeição, semelhante aos tempos primordiais. Na verdade, como o título do livro sugere, embora as Descobertas e os sentimentos que elas despertam surjam em primeiríssimo plano, Navegações tem um âmbito mais ambicioso e mais lato do que o relato e a apreciação daqueles feitos. De facto, como adverte Merleau-Ponty, o visível, tão proclamado por Sophia, está indissociavelmente ligado ao invisível e também neste caso há múltiplos significados latentes à espera de serem desocultados.

Nesse sentido, Navegações funciona como uma matrioska, pois celebra as viagens dos Descobridores, mas através delas, figura a marcha da Humanidade e do Ser, apontando para a construção de um futuro que corresponda ao aperfeiçoamento do Homem, em consonância com a doutrina de Teilhard de Chardin, que elege a união como forma de salvar a Humanidade. Simultaneamente, o livro estabelece um paralelo entre o trabalho do descobridor e o do poeta, ambos criadores de mundos (cfr. Figura 2).

Assim, do nosso ponto de vista, através da forma e do conteúdo, Navegações estabelece uma equivalência simbólica entre o processo das Descobertas (o mundo como um todo e como pátria) e a Evolução da Humanidade, a procura do Ser e a actividade do Poeta, propondo-nos um projecto de Re-começo, num 
momento histórico em que a descolonização encerra o ciclo inaugurado pelos Descobrimentos ${ }^{6}$ e se abre um novo ciclo, que ela caracteriza como um tempo de convívio novo e recreador entre os homens de todas as nações, um tempo sem dominadores e sem dominados, um tempo sem vencedores nem vencidos (cfr. Andresen 1977). Em visita a Macau em 1977, Sophia vê esse novo ciclo já em marcha, considerando que aquele é já «o lugar onde se realiza cada dia esse convívio entre homens de diversas nações, diversos cultos e diversas culturas que é o projecto do nosso presente. Lugar de diálogo e convivência viva, onde as diferenças não significam separação, mas sim a múltipla possibilidade de criação humana» (Andresen 1977, [s.p.]).

\section{As Descobertas Portuguesas em Navegações \\ Significados Reais e Simbólicos}

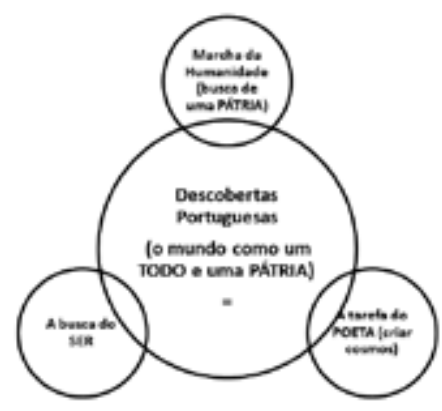

As Descobertas Portuguesas em "Navegações". Significados Reais e Simbólicos, imagem da minha autoria.

Na verdade, em sintonia com A.J. Toynbee ${ }^{7}$, Sophia $^{8}$ vê nos Descobrimentos portugueses um marco na evolução do Homem e o espantoso feito de descobrir e ligar diferentes povos, terras e culturas, um feito levado a cabo por homens que saem de sua terra para ir ver a terra inteira (cfr. Andresen 1977), por «gente do estar duplo. Gente que tem uma pátria, mas vai a caminho» (Andresen 1980,

6 «Das consequências positivas do 25 de Abril, a mais importante é a descolonização. Porque os Descobrimentos, a aventura extraordinária dos Descobrimentos, cumpre-se na independência dos povos». (Andresen 1989b, 101); «Penso que não teria escrito o livro antes da independência das antigas colónias, porque a realidade do colonialismo encobria o descobrimento» (Andresen 1985, 3).

7 «These Iberian pioneers performed an unparalleled service for Western Christendom. They expanded the horizon; and thereby potentially the domain, of the society they represented until it came to embrace all the habitable lands and navigable seas of the globe» (Toynbee 1947, 125).

8 «Para mim o tema das Navegações não é apenas o feito, a gesta, mas fundamentalmente o olhar; aquilo a que os gregos chamavam aletheia, a desocultação, o descobrimento» (Andresen 2015, 752). 
26), como é celebrado em Os Lusíadas, de Luís de Camões. Esta é a opinião da autora sobre a epopeia de Camões, o poeta cuja vida e obra reflecte o povo português, como decorre da leitura do seu poema publicado em versão manuscrita em 1983, que tem por título o nome do poeta e diz: «de Camões direi que nos é pátria/ Este preciso sabor de exílio/ Que há muito nos conhece e há muito conhecemos» (Andresen 1983b, 110).

Dos Descobrimentos resultaram vantagens incalculáveis para a Humanidade, que a autora viu concretizadas em Macau em 1977, durante a viagem que inspirou este livro. Sophia contou várias vezes como a experiência do seu primeiro olhar sobre a Ásia, vista do avião, provocou o seu maravilhamento e a recordação dos navegadores que pela primeira vez chegaram àquelas paragens, bem como do deslumbramento que devem ter experimentado e de «quantos as terão amado perdidamente» (Andresen 1983b, 107).

Nessa experiência e «como invocação desse primeiro instante do descobrir e do meu próprio deslumbramento 'aconteceram' os primeiros poemas das Navegações - alguns escritos ainda a bordo do avião» (Andresen 1983b, 107). A autora afirmou mais tarde: «escrevi os primeiros poemas simultaneamente a partir da minha imaginação, desse primeiro olhar, e a partir do meu próprio maravilhamento» (Andresen 2015, 751).

Assim, primeiro olhar, maravilhamento, recordação e imaginação integram a experiência que dá origem ao livro, devendo salientar-se que as duas últimas estão intimamente ligadas, se considerarmos que, como afirma o neurocientista António Damásio, as nossas memórias passadas e futuras, que ele inclui no conceito de «experiência integrada» (Damásio 2017, 204), são material imprescindível para o processo imaginativo, e este, para ele, «consiste na recordação de imagens e sua manipulação subsequente» (Damásio 2010, 190).

Segundo esta ideia, a imaginação de Sophia estará naquele momento ancorada em várias memórias pessoais, literárias e históricas sobre o assunto em questão, mas também em memórias do futuro imaginado, memórias que, em conjunto, afectarão todo o processo de percepção e captação do real e da sua representação. Nesse entendimento, pela mesma imaginação, Sophia poderá construir mundos possíveis, ou até impossíveis, pois, como defende Eugen Fink, a imaginação «possède en totalité un monde possible» (Fink apud Westphal 2007,212), e a autora anda em busca da construção das «cidades da equidade» (Andresen 2015,611 ), ainda que saiba «que não serão a total equidade. Ficaremos sempre a meio caminho» (Andresen 1982, 4).

Nestas circunstâncias, também o olhar, que ocupa lugar de destaque na obra poética de Sophia', e por maioria de razão em Navegações, está necessariamente afectado pela subjectividade da observadora, pois como afirmou Merleau-Ponty, «a visão é o encontro, como numa encruzilhada, de todos os aspectos do Ser» (Merleau-Ponty 2018, 68). Ora Sophia anda sempre à procura de $<$ o olhar que busca a aparição do mundo, o surgir do mundo, o emergir do visível e da vi-

9 «De facto, tenho uma grande confiança no olhar» (Andresen 1985, 3). 
são» (Andresen 2015, 813), mas se o visível é um dos aspectos mais destacados neste e noutros livros, aquele filósofo lembra que «o que é próprio do visível é ter uma dobragem de invisível em sentido estrito, que ele torna presente como uma certa ausência» (Merleau-Ponty 2018, 67), uma ideia que a autora ilustra bem em Navegações, ao descrever como «À luz do aparecer a madrugada / Iluminava o côncavo de ausentes / Velas a demandar estas paragens» (Andresen $2015,725)$. Assim, de acordo com aquele filósofo, o acto de olhar provoca um encontro entre o sujeito e o objecto, onde «é impossível dizer que aqui acaba a natureza e começa o homem ou a expressão» (Merleau-Ponty 2018, 68). Dito de outra forma, no acto de olhar, «as coisas passam por dentro de nós, assim como nós passamos por dentro das coisas» (Merleau-Ponty 1984, 121), sendo que estas trazem coladas a si outras visões para além da nossa, porque «o objeto é visto [...] a partir de todos os tempos, assim como é visto de todas as partes» (Merleau-Ponty 1999, 106).

Em suma, aquele primeiro olhar de Sophia sobre o Vietnam, pelas recordações que mobiliza, realiza a ideia de Rossana Bonadei, quando esta diz que «le regard est intertextuel; il se construit dans le temps par divers processus de différentiation et d'assimilation et se rive aux nombreux textes à travers lesquels l'esprit et l'imagination ont épousé l'espace» (Bonadei apud Westphal 2007, 205). Com efeito, este primeiro contacto visual de Sophia com o Oriente corresponde àquilo que Eugen Fink chamou uma «archi-impression», ou seja, um processo em que «le présent se produit (zeitigt sich) dans une multiplicité de phases impressionnelles, et de telle sorte que celles-ci fondent par dépendance et réciprocité le tout du présent» (Fink apud Westphal 2000).

Neste sentido, em Navegações, a captação do espaço e a sua representação correspondem a um processo de desterritorialização (conceito de Deleuze e Guattari), funcionando como «une sortie du présent - mais aussi une sortie du lieu» (Westphal 2007, 205), onde, neste caso, se conjugam vários olhares, que poderão ser perceptíveis para o leitor naquilo que a autora afirmou ser «um intricado jogo de invocações e ecos mais ou menos explícitos» (Andresen 2015, 751) presentes na obra, alguns dos quais foram indicados pela própria em «Notas sobre Navegações» (Andresen 1983b).

De facto, este livro é, como não podia deixar de ser atendendo à sua temática, uma obra predominantemente intertextual, que convoca em primeira linha Os Lusíadas, de Camões, e Mensagem, de Fernando Pessoa. No entanto, a intertextualidade com estas e outras obras não obsta à apresentação de uma visão muito própria e original sobre o assunto tratado.

Na verdade, poder-se-á dizer que Navegações propõe um mundo possível, vendo no presente um momento inaugural, um re-começo, uma segunda origem, perspectivados a partir de um olhar orientado para o futuro, mas que é também sobre o passado e o presente, e por isso necessariamente intertextual, mas sem que esse facto impeça uma perspectiva nova e pessoal.

Em nosso entender, a originalidade dessa perspectiva decorre do projecto já enunciado e de uma visão particular que parte da experiência pessoal da relação inicial da autora com o Oceano, que a leva a colocar em primeiro plano a vivên- 
cia das navegações como uma «epopeia do espanto», passando para segundo plano os factos e os objectivos históricos dos Descobrimentos.

Segundo a autora,

Esse espanto perante o mar, que é um espanto perante o mundo, espanto maravilhado e um pouco arcaico - o que está no sorriso da estátua arcaica - é o maravilhamento do homem diante do descobrir do mundo: é um maravilhamento que eu reconheci nas navegações portuguesas, que foram uma epopeia do espanto (Andresen 1990, 127).

A perspectiva geocrítica explica este espanto perante o mundo, dizendo que «l'espace flotte et s'ouvre sur l'étonnement», pois «il se renouvelle parce que, stricto sensu, il prête lieu au «"déploiement de la question étonnante” (Fink apud Westphal 2007, 212).

\subsection{Da forma ao sentido: a relação forma-conteúdo}

Dada a sua importância, começamos por analisar a estrutura do livro, o todo e as partes, a ordem, título e subtítulos, nomes e números.

Nos textos de Sophia é frequente a referência à «forma justa», sendo, aliás, o título de um poema (Andresen 2015, 710) e um valor em busca. O uso do adjectivo «justo», também muito frequente, é, no entanto, plurissignificativo, remetendo tanto para justiça como para justeza, correspondendo num caso a um valor moral e no outro aos valores de adequação, harmonia, proporção, equilíbrio, medida. O segundo caso materializa-se em nomes, números, ordem, concebidos como produtores de sentidos, que, conjuntamente com os significados das palavras, convergem sempre para o alcance da verdade.

No poema referido, a «forma justa» corresponde à «perfeição do universo», sendo intrínseca e consubstancial à verdade do poema, de acordo também com as ideias de Heidegger. Diz Sophia que «há um desejo de rigor e de verdade que é intrínseco à íntima estrutura do poema e que não pode aceitar uma ordem falsa» (Andresen 2015, 894). Por razões óbvias, o mesmo se aplica a um livro, criado como um todo orgânico. Esta ideia implica o par forma-conteúdo na produção de sentidos, já que uma e outro estão intimamente imbricados e se reclamam mutuamente.

Nestas circunstâncias, a estrutura externa e interna de Navegações, a sequencialidade, os elementos paratextuais e o uso de algumas técnicas narrativas produzem sentidos fundamentais do livro. Em nosso entender, esses sentidos são cruciais para construir uma interpretação global e para integrar o livro no projecto que acima enunciámos.

O livro é composto por 25 poemas, distribuídos por três partes, muito assimétricas. A primeira edição integra ainda 5 mapas da época dos Descobrimentos, distribuídos pelas segunda e terceira partes (cfr. Andresen 1983a).

No que respeita aos mapas, os quatro primeiros, que representam partes do globo, interagem com textos e o último, um mapa-mundo, com todo o livro, mas por si só e pela sua sequencialidade contam histórias e produzem vários sentidos, incluindo o olhar de quem os fez, na opinião da autora. Isto aponta para a frase 
de Peter Turchi, completada por R. Tally: «To ask for a map is to say, "Tell me a story" $\gg$ to which may be added, and vice versa» (Tally 2018, 6).

Relativamente às partes, a sua sequencialidade não é numerada, decorre apenas da sua distribuição no espaço do livro, facto que pode ser explorado a nível de significado. Já internamente, na segunda e terceira partes, os poemas aparecem identificados em numeração romana, o que aponta para a importância da sua ordem na parte e no todo.

A primeira parte, Lisboa, tem 1 poema; a segunda, Ilhas, tem 7; a terceira, Deriva, tem 17 (cfr. Figura 3).

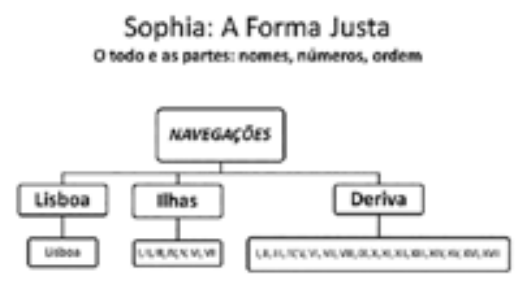

Sophia: A Forma Justa. O todo e as partes: nomes, números, ordem, imagem da minha autoria.

Assim, num primeiro olhar, e em termos quantitativos, poder-se-ia dizer que à terceira parte, Deriva, é atribuída uma importância superior, mas essa é uma expectativa que pode não se confirmar. No entanto, os números, esta divisão e esta ordem produzem sentidos não negligenciáveis no contexto do livro e do universo poético da autora, como pretendemos demonstrar.

A nosso ver, conjuntamente com uma estrutura linear portadora de valores simbólicos (como na figura 3), o livro apresenta uma estrutura circular que pode ser interpretada como proposta de um contínuo recomeço (cfr. Figura 4).

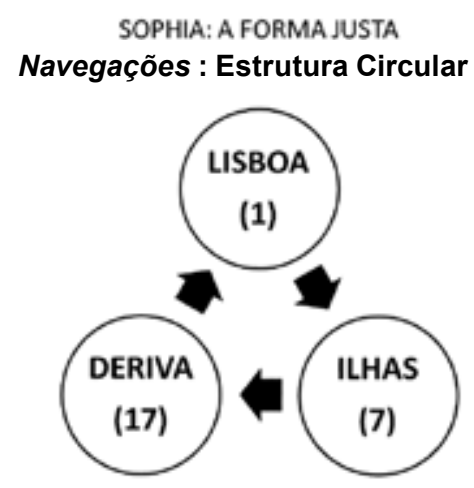

Sophia: A Forma Justa. «Navegações»: Estrutura Circular, imagem da minha autoria. 
Em suma, todos estes elementos convocam uma interpretação e sugerem uma análise simbólica, partindo do princípio de que «les nombres, comme les noms, quand on les énonce, déplacent des forces qui établissent un courant, à la manière d'un ruisseau souterrain, invisible, mais présent» (Chevalier e Gheerbrant 1989, 678).

Na verdade, Sophia constantemente realça o poder e a função dos nomes, sendo os números menos directamente referidos. No entanto, estes estão necessariamente incluídos no conceito de «forma justa» e na harmonia que constantemente reclama, como faz no poema Brasília (Andresen 2015, 566), onde significativamente são mencionados o «número», «A essência universal das formas justas», e Pitágoras, o filósofo grego que afirmou que «tudo é número» e que este é o princípio de todas as coisas. Recorde-se que, como lembram Chevalier e Gheerbrant $(1989,678)$, aos números estão atribuídos múltiplos poderes e valores simbólicos, que alguns consideram superiores aos da palavra.

No caso deste livro, a associação dos nomes, dos números e da sequencialidade revela-se fundamental para a construção de uma interpretação que abranja a plurissignificação que ele condensa, e que os textos validam e completam. Integrar estes elementos na análise, permite concluir que as viagens históricas dos Descobridores funcionam também como alegoria (cfr. Figura 2). Para além disso, as potencialidades significativas destes elementos permitem ao leitor proceder a uma «desterritorialização» e a projectar mundos possíveis, que o livro aponta como alternativas ao mundo real do presente.

Os nossos esquemas das figuras 3 e 4 mostram todos os elementos da composição do livro, em estrutura linear e circular, sendo esta última já fruto de uma interpretação.

No que concerne os nomes, o título do livro e o das partes estão intimamente articulados pelos seus significados. Navegações, na sua forma plural, remete factualmente para a viagem do sujeito poético (barco e avião), para as viagens dos navegadores portugueses e para as navegações mediterrânicas. Estas últimas aparecem no início e no final do livro, formando um círculo e perfazendo uma viagem de circum-navegação (cfr. Figura 4). Porém, os valores simbólicos construídos pelo livro e pela restante obra da autora ou decorrentes da tradição cultural adicionam-se aos significados literais apresentados.

Em suma, o livro apresenta o Homem como um Homo Viator (conceito de Gabriel Marcel), em navegação/ evolução contínua (cfr. Figura 5).

Em termos de significado, a autora define Navegação num poema com este título, no mesmo sentido que lhe é atribuído no livro, no sentido de aparição, de descoberta.

Distância da distância derivada

Aparição do mundo; a terra escorre

Pelos olhos que a vêem revelada.

E atrás um outro longe imenso morre (Andresen 2015, 153).

Contudo, os valores simbólicos vindos da tradição cultural são igualmente relevantes na análise do livro, nomeadamente os que vêm do cristianismo e 


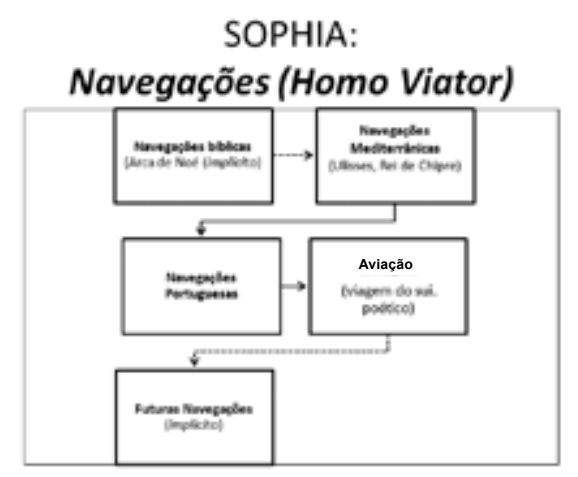

Sophia: "Navegações" (Homo Viator), imagem da minha autoria.

da Grécia. Dos vários significados de «navegação» indicados por Chevalier e Gheerbrant $(1989,661)$, interessam-nos especialmente o caso da Bíblia onde, com base no episódio da Arca da Aliança (Gen., 6-9), a navegação é vista como meio de atingir a paz, o estado central, o nirvana; no caso das navegações gregas, a busca das ilhas ou do Tosão de Ouro representa a procura do centro espiritual primordial ou da imortalidade.

Estes valores simbólicos estão claramente associados à simbologia das ilhas, pois segundo os mesmos autores, «l'île, à laquelle on ne parvient qu'à l'issue d'une navigation ou d'un vol, est par excellence le symbole d'un centre spirituel primordial. [...] Elle représente un Centre primordial, sacré par définition» (Chevalier e Gheerbrant 1989, 519-20). Desenvolveremos este ponto mais à frente.

Também o título da terceira parte, Deriva, está articulado com o título do livro, pois, como indica uma das definições de dicionário, a palavra tem o sentido de «desvio de um navio ou dum avião por efeito de uma corrente ou do vento», e o significado da expressão à deriva reforça este mesmo sentido, sublinhando 'ao sabor das correntes ou dos ventos'. A relação com o título Lisboa é mais subtil e será analisada posteriormente (cfr. infra, ponto 2.2).

Relativamente aos números, os valores simbólicos atribuídos àqueles que estão envolvidos na estrutura $(1,3,5,7$ e 17) produzem efeitos relevantes na interpretação do livro. Quanto ao todo, destacam-se o 3 (partes) e o 5 (25 poemas $=5 \times 5$ e 5 mapas), estando o primeiro associado ao Céu e o segundo às hierogamias (casamento entre o Céu e a Terra).

Quanto às partes, os significados de 1,7 e 17 são muito importantes individualmente, mas também na sua ordem no livro e na combinação com os títulos das partes que representam.

O 1 é o Criador, a unidade primordial, o princípio; o 7 está associado à Criação na Bíblia (7 dias), é considerado o número da perfeição e representa a soma $3+4$, o Céu e a Terra; 17 corresponde à razão $9 / 8$, relativa à música, mas tem para nós a feliz coincidência de corresponder às datas do episódio bíblico do Dilúvio, pois as chuvas começaram no $17^{\circ}$ dia do segundo mês e foi também no $17^{\circ}$ dia 
do sétimo mês que a arca de Noé encalhou sobre o Monte Ararat (Gen., 7-8), quando as águas já estavam a baixar. Este episódio corresponde a uma segunda Criação, um re-começo, significado relevantíssimo no universo de Sophia, que se liga também ao valor simbólico das Ilhas.

Adicionalmente aos valores dos números, a posição ocupada por cada poema na estrutura global ou parcial pode ganhar sentidos ou funções especiais, permitindo, por exemplo, associações por contiguidade, por simetria ou assimetria, caso do primeiro e do último.

O último poema articula todos os elementos abordados ao longo do livro, mas reunindo-os na arte. Poeta, navegadores, navegações e errância, conjugam-se na arte manuelina, estilo directamente ligado aos Descobrimentos. A arte surge, assim, num lugar estratégico, ligada à positividade que a errância assume na mundividência que o livro promove, errância em que a autora «manuelinamente entrelaça» a sua «própria errância» (Andresen 1983b, 108). Este tema surge no livro introduzido subtilmente pelo poema anterior, sobre o Rei de Chipre, figura da Grécia antiga considerada criadora das artes e de várias invenções, que recusou participar na Guerra de Tróia e representa a errância das navegações mediterrânicas que precederam as portuguesas, como a própria autora afirmou (Andresen 1983b, 108). No entanto, o leitor atento teria já descoberto a função da arte no primeiro poema do livro.

\subsection{Alguns temas e seu tratamento. Lisboa}

Digo:

«Lisboa»

Quando atravesso - vinda do sul - o rio

E a cidade a que chego abre-se como se do seu nome nascesse

Abre-se e ergue-se em sua extensão nocturna

Em seu longo luzir de azul e rio

Em seu corpo amontoado de colinas -

Vejo-a melhor porque a digo

Tudo se mostra melhor porque digo

Tudo mostra melhor o seu estar e a sua carência

Porque digo

Lisboa com seu nome de ser e de não-ser

Com seus meandros de espanto insónia e lata

E seu secreto rebrilhar de coisa de teatro

Seu conivente sorrir de intriga e máscara

Enquanto o largo mar a Ocidente se dilata

Lisboa oscilando como uma grande barca

Lisboa cruelmente construída ao longo da sua própria ausência

Digo o nome da cidade

- Digo para ver

(Andresen 2015, 719). 
Começamos por Lisboa, que é simultaneamente uma parte do livro constituída por 1 poema e um poema não numerado.

Do ponto de vista estrutural, esta parte e o referente espacial que lhe está associado, Lisboa, ganha toda a carga simbólica do número Um, como o Criador, a unidade primordial, o começo. Na sua contiguidade com as partes seguintes, o 1 realça o seu valor simbólico como número que dá causa à dualidade como multiplicidade e o regresso à unidade final. $\mathrm{O}$ facto de não haver numeração autoriza a interpretação de que não tem princípio nem fim, tal como Deus, o Criador. Neste sentido, Lisboa é apresentada como a Origem dos Descobrimentos, tarefa que continuará em marcha. Esta interpretação é reforçada pelo facto de haver um outro poema dedicado a Lisboa, poema $X V$ da III parte (Andresen 2015, 747), podendo, por isso, ter sido o encerramento do livro, facto que não se verifica efectivamente. Na verdade, a Lisboa deste poema é já outra, é a cidade do presente, caracterizada pela negatividade de um «Tédio sem Tejo», é uma «Inversa navegação», uma «anti-pátria» hostil, que a autora disse corresponder às «diversas Reboleiras de Lisboa, atrozes e sem Tejo» (Andresen 2015, 750), ou seja, é a periferia que prolonga a cidade inicial, de forma descaracterizadora.

Por isso, a realidade «cinzenta» desta última Lisboa deverá ser ultrapassada e, tal como o livro que tem mais dois poemas que reintroduzem o tema das navegações, da errância e da arte, as navegações deverão continuar sob diversas formas, do mesmo modo que a viagem de avião do sujeito poético, vista como uma «navegação abstracta» (Andresen 2015, 724), ilustra a continuação das viagens dos navegadores de quinhentos.

Do ponto de vista do conteúdo deste primeiro poema, verificamos que ele reforça estas interpretações e acrescenta outros sentidos muito importantes, havendo alguns pontos que iremos realçar aqui, a saber, Lisboa como mito, o dizer projectante e Lisboa como 'uma grande barca'.

Relativamente ao primeiro ponto, constatamos que no poema a cidade é captada através da visão do sujeito poético que chega, vinda do sul (vv.1-3). Aparentemente sem importância, este facto é fundamental em termos simbólicos, já que:

1. o sujeito poético se assume ele próprio como navegador, tal como em Ilhas II, uma analogia com Ulisses da Odisseia, também ele navegador e narrador;

2. de forma muito subtil, a situação enunciada remete para o mito da fundação de Lisboa por Ulisses, exactamente vindo do Sul, durante a sua errância na viagem de regresso a casa, mito referido por Camões e Fernando Pessoa.

Em consequência, este processo de captação de imagem e a correlativa evocação e invocação do mito transforma Lisboa num achado proporcionado pela errância/ deriva, e simultaneamente liga-a às navegações gregas, estabelecendo uma ponte, que será retomada no penúltimo poema do livro, que tem como assunto o Rei de Chipre, ilustrativo das navegações mediterrânicas. Adicionalmente, este facto exemplifica por antecipação os achados e as criações dos marinheiros que a terceira parte reportará.

Assim, estruturalmente, este mito liga a primeira e a terceira partes, permitindo a formação de uma estrutura circular (cfr. Figura 4), que do ponto de vista 
semântico e ideológico institui o carácter contínuo da navegação, tornando-a, assim, um traço característico da Humanidade, que, deste ponto de vista, continua em Evolução, de acordo também com a doutrina de Teilhard de Chardin, cientista referido por Sophia (Andresen 2015, 894).

Neste sentido, o passado e o presente são apenas momentos de um devir da História da Humanidade, que prenunciam o futuro, ilustrado no livro pela viagem de avião do sujeito poético, que sucedeu às navegações marítimas. Por outro lado, também a História confirma esta tese, pois no presente da enunciação do livro, o Homem já tinha «navegado» para a Lua e hoje, como sabemos, todos navegamos num espaço virtual.

Assim, Lisboa é simultaneamente ponto de chegada e ponto de partida, sendo que o poema e o livro colocam a chegada em primeiro lugar, estabelecendo um círculo e activando todos os valores simbólicos desta forma geométrica. Para além disso, o significado do retorno à Unidade é também activado.

Esta abertura alerta para o valor e a função do mito ao longo do livro e desenvolve o significado do verso de Pessoa «o mito é o nada que é tudo», do poema Ulisses, de Mensagem, trazendo à memória a ideia de Heidegger, quando ele diz que «myth means the telling word» (Heidegger 1968, pos. 370-377).

O segundo ponto que queremos abordar neste poema é o facto de o «dizer» preceder o «ver» (Digo para ver), sendo, por isso, um «dizer projectante» (Ansagen), tornando o poeta de alguma forma criador do real, atribuindo-se, assim, à Linguagem Poética uma dimensão performativa, tal como teorizado por Heidegger e reivindicado e praticado por Sophia.

Assim, ritualmente, o sujeito poético recria a fundação de Lisboa por Ulisses e assume o papel de Deus na criação do Universo, que criou e fez aparecer o Real através da palavra, produzindo epifanias (Gén., 1.3).

Desta forma, em Navegações, o acto de «nomear» (cfr. vv. 1-2, 4, 19-20) produz efeitos imediatos sobre o real (cfr. Rocha, 1994), fundando-o por desvelamento. Esta prática corresponde à ideia de Heidegger que, baseando-se nos gregos, considera que «"to call" means to set in motion, to get something underway» (Heidegger 1968, pos. 1703-1711), conferindo-se, assim, à Linguagem uma função essencial na criação do Real, através do seu poder de desvelamento das coisas e dos seres, aletheia, incluindo o desvelamento do Ser.

$\mathrm{Na}$ linha de Heidegger, Sophia parece acreditar que «language is the house of Being. In its home man dwells. Those who think and those who create with words are the guardians of this home» (Heidegger 1993, 217), porque «a Poesia é a fábula da desocultação do ente» (Heidegger 2008, 59) e «A essência da poesia é a instauração da verdade» (Heidegger 2008, 60).

Neste sentido, a acção do Poeta é similar à do descobridor que irá proceder à desocultação do real, à sua nomeação e, posteriormente, ao seu mapeamento, sendo, por isso, igualmente criadores de mundos, pois os navegadores «Iam de cabo em cabo nomeando / Baías promontórios enseadas: [...] E as coisas [...] / Uma por uma ao seu nome respondiam / Como sendo criadas» (Andresen 2015, 500). 
O terceiro ponto que queremos realçar neste poema deriva também da localização e posição do sujeito poético na sua captação da cidade (focalização). Captada do Sul, Lisboa aparece no poema como uma barca oscilante nas águas do estuário do Tejo, bem próximo da sua foz no mar Oceano, portanto, pronta a flutuar para o Atlântico, como a Arca de Noé navegou nas águas do Dilúvio. Diz o poema: «Enquanto o largo mar a Ocidente se dilata / Lisboa oscilando como uma grande barca».

Esta visão parece figurar os ventos da Geografia e da História a empurrar Lisboa para realizar os feitos dos Descobrimentos, da mesma forma que empurraram Ulisses para a sua fundação e originaram a sua partida. Esta imagem traz à memória o título Lisbona fugge dalle acque, atribuído por Gianfranco Dioguardi ao seu artigo sobre Lisboa publicado em Il Corriere della Sera, de 24/01/1992, e seguramente lembrará aos leitores o Padrão dos Descobrimentos, monumento erigido numa forma temporária em 1940 e reconstruído na sua forma definitiva em 1960, para comemorar os 500 anos da morte do Infante Dom Henrique, o grande impulsionador dos Descobrimentos.

Assim, a localização e a configuração geográfica de Lisboa traçam-lhe o destino, porque, como escreveu Bertrand Westphal, ela é «le pivot d'un rêve. Lisbonne est ailleurs» (Westphal 2006, 19). Há, pois, uma espécie de fatalismo geográfico que a torna móvel e a empurra para o Oceano, pois, diz Westphal, «dès que le regard se porte vers l'ouest, Lisbonne devient le commencement d'une dérive océanique qui en fait le départ de toute navigation réelle ou imaginaire en direction des Amériques et de l'Afrique» (Westphal 2006, 17). Também Sophia sente este efeito do lugar, como mostra o seu poema Tejo (Andresen 2015, 853).

Virada para a distância atlântica, Lisboa é uma cidade «flutuante», um barco, escreveu José Cardoso Pires, o que faz dela um espaço de «constante déterritorialisation» (Westphal 2006, 16), apelando ao imaginário e ao infinito. Neste lugar, e talvez só neste lugar, os marinheiros sentiram «essa antiga atracção do oceano» (Martins 1987, 9), foram hipnotizados «pela infinita vastidão azul» (Martins 1987, 9), e arrebatados pelo «murmúrio das sereias do mar, cantando na vaga espumosa que se parte contra as rocas da Arrábida e de Sintra, dançando na areia loura ao sopro do vento...» (Martins 1987, 9).

Neste sentido, a localização geográfica de Lisboa, pela sua exposição ao Longe, convoca a questão do Horizonte, não apenas como linha, mas sobretudo como estrutura, o horizonte que desafia, que atrai e repele, que «est la présence de l'ailleurs, la mise en scène de sa possibilité et en même temps de son exclusion» (Westphal 2011, pos. 1484).

Em suma, assim configurada, como «un morceau flottant d'espace, un lieu sans lieu, qui vit par lui-même, qui est fermé sur soi et qui est livré en même temps à l'infini de la mer» (Foucault 1984), Lisboa assume o valor de uma heterotopia no sentido de Michel Foucault, que vê no navio a maior reserva de imaginação desde o século XVI, razão pela qual «le navire, c'est l'hétérotopie par excellence» (Foucault 1984, [s.p.]). 


\subsection{Ihas. Deriva}

A segunda e terceira partes do livro tratam directa e explicitamente das navegações mediterrânicas, das viagens do sujeito poético e dos descobridores. No entanto, do ponto de vista simbólico, autorizam a construção de vários significados, como veremos.

A segunda parte, Ilhas, começa com o relato e a descrição da viagem de avião do sujeito poético ao Oriente e fecha com um poema sobre a morte de D. Sebastião, acontecimento histórico que marca o final dos Descobrimentos, facto que o sujeito poético lamenta. A nosso ver, este lamento significa simbolicamente que este processo exploratório não pode parar, ideia confirmada pela continuação do livro.

Quanto ao conceito Ilhas, ele é para a própria autora simultaneamente real e metafórico. Ele corresponde a ilhas reais, mas representa também a «ideia de descobrimento» (Andresen 2012) e os «momentos e lugares que foram como ilhas no meio da confusão» (Andresen 1989a, 56R).

Em qualquer destes casos, o valor atribuído às ilhas é claramente positivo, podendo ser associado à crença da autora na existência de 'paraísos' temporários, que já referimos. Porém, como já mencionado, a mitologia, a simbologia, e o imaginário das ilhas tem uma grande tradição, como referem Chevalier e Gheerbrant (1989, 519-20), e não é por acaso que elas surgem também em Os Lusíadas (Ilha dos Amores) e Mensagem (Ilhas Afortunadas), com uma função de prémio e recompensa.

Entretanto, um texto interessantíssimo de Gilles Deleuze, intitulado L'île Déserte, faz uma preciosa análise sobre o fenómeno das Ilhas, na sua relação com o Homem e o Cosmos, apresentando múltiplos aspectos que se aplicam ao universo poético de Sophia e em particular a Navegações. Destacamos apenas alguns deles, que nos parecem pertinentes para a interpretação deste livro.

Para este pensador, L'île Déserte é «un modèle, un prototype de l'âme collective (Deleuze 2002, 16), porque, realça ele, «l'île, c'est aussi l'origine, l'origine radicale et absolue» (Deleuze 2002, 12), não a primeira mas a segunda origem, porque a ilha não é «la création elle-même mais la re-création, non pas le commencement mais le re-commencement. Elle est l'origine, mais l'origine seconde. A partir d'elle tout recommence» (Deleuze 2002, 16). Segundo o autor, esta função de segunda origem «donne tout son sens à l'île déserte, survivance de l'île sainte dans un monde qui tarde à recommencer» (Deleuze 2002, 17). Este recomeço está previsto desde o início, pois, diz o autor, «il n’y a pas une seconde naissance parce qu'il y a eu une catastrophe, mais l'inverse, il y a catastrophe après l'origine parce qu'il doit y avoir, dès l'origine, une seconde naissance $\gg$ (Deleuze 2002, 16).

Como já dissemos, esta interpretação de Deleuze parece adaptar-se com perfeição ao projecto de Sophia, e em particular ao caso de Navegações, cujo sujeito poético confessa abertamente o seu fascínio pelas ilhas, no poema $X V I$ da III parte, quando diz «Clareza das ilhas / Que tanto busquei» (Andresen 2015, 748). 
Por outro lado, esta visão de Deleuze legitima e reforça a nossa interpretação feita a partir dos números 7 e 17, lendo o primeiro como a «criação» original e o segundo como «re-criação», de acordo com o mito bíblico do Génesis, uma interpretação sustentada por vários dados explícitos nos textos do livro. Curiosamente, também Deleuze liga a ideia da segunda origem ao mito do Dilúvio e à mitologia das ilhas, dizendo que

Il est bien connu comme mythe du déluge. L'arche s'arrête au seul endroit de la terre qui n'est pas submergé, lieu circulaire et sacré d'où le monde recommence. [...] Voilà la première création prise dans une recréation, celle-ci concentrée dans une terre sainte au milieu de l'océan. Seconde origine du monde plus importante que la première, c'est l'île sainte (Deleuze 2002, 17).

Em Navegações, as ilhas surgem como busca e sonho do sujeito poético e como realidade observada, percepcionada pelo mesmo e pelos navegadores. Estabelecendo um paralelo com a análise de Deleuze, diríamos que este sonho corresponde já a uma situação de ruptura e a um desejo de recomeço do sujeito, o que é, aliás, continuamente afirmado na poesia de Sophia. Diz Deleuze que «rêver des îles, [...], c'est rêver qu'on se sépare, qu’on est déjà séparé, loin des continents, qu'on est seul et perdu - ou bien c'est rêver qu'on repart à zéro, qu'on recrée, qu'on recommence» (Deleuze 2002, 12).

Literalmente, no livro, as ilhas são captadas pelo sujeito poético (Ilhas I), e num segundo momento, pelos navegadores (Ilhas IV). Em ambos os casos, surgem como aparição, epifania, que extasia e espanta o observador. Para além da presença e do significado das ilhas, o conteúdo da segunda e terceira partes abrange vários aspectos, de que iremos destacar alguns pontos.

No que respeita aos feitos dos navegadores, em Ilhas o sujeito poético celebra a coragem, a ousadia, a aventura, a busca da verdade e da «inteireza do possível» (Ilhas II) por aqueles que realizaram as descobertas, enfrentando o desconhecido e o «inavegável» (Ilhas VI). Ao mesmo tempo, é indicado o prémio recebido, concretizado no encontro com a verdade e a totalidade, e na percepção de que o verdadeiro excede o desejado, o sonhado e o imaginado (Ilhas $I V, V, V I)$. Além disso, Sophia destaca o surgimento avassalador de um Real totalmente novo, caracterizado pelo excesso, como diz Nava (Nava 2004, 174), e que produz um efeito de rendição e espanto aos olhos dos contempladores. Este real surge em Navegações como aparição, como epifania, e assume as marcas que Deleuze e Guattari atribuem ao meio geográfico: a materialidade, a multiplicidade, a emergência e as interacções entre humano e não-humano (cfr. Labussière 2014, 71-73).

A imponência avassaladora desse real, visível na recorrência anafórica do verbo «ver», nas expressões «a veemência do visível» (Andresen 2015, 727) e $\ll$ o brilho do visível frente a frente» (Andresen 2015, 728), exprime-se também através do reforço anafórico dos deícticos de lugar «aqui» e «ali (Ilhas $I V, V, V I)$, conjugados com os deícticos ou pronomes pessoais que indiciam a co-presença do Homem e do espaço, numa situação de frente a frente. Efectivamente, para Sophia, a experiência das Descobertas «foi a aventura do olhar, 
da entrega ao visível, do homem» (Andresen 1986, 65), vivida com espanto e deslumbramento.

Referindo-se a este assunto, Westphal diz que «le découvreur ne relatait qu'imparfaitement la portée de son émerveillement. En revanche, [...] il n'allait pas tarder à inclure sa découverte dans les rhombes ou les rectangles d'une carte. Entre ces deux moments, il éprouvait le frisson de l'espace; il se laissait pénétrer par la nouveauté; il était en suspens dans quelque chose qui n'avait pas encore pu être transformé en un lieu que l'on contrôle» (Westphal 2011, pos. 2436).

$\mathrm{Na}$ época dos Descobrimentos, este espanto do olhar perante o novo estendeu-se à Europa, que, no regresso dos navegadores, recebeu «as suas descrições, pedras, frutos, animais e homens» (Brito 1983, 64) e, bem entendido, os mapas, aqueles mapas onde, segundo Sophia, «ainda é visível o espanto do olhar inicial» (Andresen 2015, 751), alguns dos quais integram a primeira edição de Navegações.

Esta emergência do real em toda a sua força e a respectiva apreensão pelos humanos, na perspectiva do sujeito poético, abole «memória e tempo» (Andresen 2015,723 ) e instaura, assim, o tempo absoluto, a eternidade.

O verso «Navegavam sem o mapa que faziam» (Andresen 2015, 728) mostra o legado para a humanidade, uma ideia que será retomada e reforçada na terceira parte, no poema $X I V$, que sugere a herança deixada à humanidade pelos Descobrimentos, facto irreversível que continuará o seu caminho mesmo sem aqueles que o iniciaram.

A terceira parte do livro elege a Deriva como assunto e as consequências que dela resultam, especificando aspectos e eventos, valorizando os encontros inesperados trazidos pelo acaso, oferecidos pela errância, como o título indica. Esta parte apresenta um jogo de oposições que ocorre entre poemas, mas também dentro do próprio poema, visível no uso frequente de conjunções adversativas e na aproximação de dados ou aspectos contrastantes. Essas oposições incluem: os objetivos estabelecidos e os alcançados (II, VIII); sucessos e fracassos (III, IV); a seleção do sujeito poético e a de outros repórteres (VI, VII); experiências positivas e negativas (IX, XII, XIII). Os três últimos poemas correspondem ao encerramento estrutural do livro e afirmam ou reafirmam alguns valores relativos à arte, à paz e à deriva, perspectivados como intrínsecos à condição humana.

Em relação aos objetivos das descobertas, o livro aponta aqueles que historicamente são considerados, económicos e religiosos (II, VIII), mas o sujeito poético destaca como o espanto causado pelo Real se tornou o guia que conduziu os descobridores: «Era a rota do oiro / Porém [...] / O espanto nos guiava» (Andresen 2015, 734).

Um dos pontos mais importantes desta parte é o encontro com o Outro, a maneira como ocorreu e a avaliação que é feita. O poema VIII faz uma súmula deste encontro com o Outro, tanto humano como não humano, recolhendo os aspectos apresentados mais individualmente noutros poemas. Na verdade, nestas duas partes, sujeito poético e navegadores são confrontados com uma si- 
tuação beyond e in between, que os coloca entre duas culturas e face à alteridade, uma situação em que

These "in-between" spaces provide the terrain for elaborating strategies of selfhood - singular or communal - that initiate new signs of identity, and innovative sites of collaboration, and contestation in the act of defining the idea of society itself (Bhabha apud Soja, 2016, 143).

A alteridade encontrada envolve pessoas, natureza, sociedade, religião, arte, língua e cultura (poema VIII) e provoca reações de visitantes e visitados.

Diante do Outro humano, o sujeito poético aponta as diferenças, mas ela destaca principalmente a maneira como essas diferenças não impediram a compreensão e o contacto pacíficos e, acima de tudo, a proximidade desse Outro com o primeiro homem bíblico, como a associação com «a primitiva manhã da criação» (Andresen 2015, 739) confirma, aspecto que se enquadra no projecto da autora. Significativamente, esses homens estão «nus» (V,VI, VII, VIII) e mantêm «ainda cor de barro» (Andresen 2015, 739), o que aponta para o homem original criado por Deus no Génesis, o homem criado a partir do barro, portanto profundamente conectado com a Terra e o Céu, como pode ser visto no poema VI, logo, em perfeita harmonia com os elementos, em linha com outros textos da autora ${ }^{10}$.

Essa visão do Outro coincide com a que Deleuze traça dos habitantes das ilhas desertas (habitadas) que foram encontradas pelos antigos exploradores («l'homme qui se précède lui-même, un prototype» (Deleuze 2002, 13), e enfatiza as características intrínsecas que tornam as ilhas espaços de recomeço.

É, portanto, a consciência da perda de valores originais pelo homem ocidental, que contém implícita «une certaine critique de la modernité, qui invite à interroger les structures de notre langage, notre conception du corps ou encore notre conception du temps et du progrès $\gg$ (Labussière 2014,74), uma ideia que é uma constante na vida e na obra da autora, como testemunha uma entrevista radiofónica de 1974, onde Sophia considera que a poesia africana preservava valores essenciais do homem, que no Ocidente já tinham sido perdidos. O poema O Primeiro Homem (Andresen 2015, 164) sintetiza as características deste modelo humano.

Neste sentido, a visão de Sophia sobre as terras descobertas, corresponde à ideia de E. Saïd, quando este diz que:

The Orient therefore alternated in the mind's geography between being an Old World to which one returned, as to Eden or Paradise, there to set up a new version of the old, and being a wholly new place to which one came as Columbus came to America, in order to set up a New World. [...] Certainly neither of these Orients was purely one thing or the other (Saïd 1979, 58).

Assim, na visão de Sophia, as terras descobertas ou encontradas são vividas como utopias ou funcionam como heterotopias, no sentido de Foucault. Elas colocam o homem ocidental numa situação in-between, e devolvem-lhe, através 
da imagem do Outro, a sua própria imagem, já degradada, no entender da autora. Simultaneamente, ela mostra-lhe os caminhos a percorrer e esses são caminhos de regresso à origem.

Em suma, as viagens dos descobridores são o encontro com o Outro, o diferente, mas elas são também o reencontro com o Eu original e um regresso às Origens, ou seja, um reencontro com os tempos primordiais, o Paraíso Perdido, são por isso uma viagem iniciática, que aponta para a descoberta do Ser.

\section{O Encontro do Ser}

A nosso ver, esses encontros também representam metaforicamente a busca e a descoberta do Ser, nos termos de Heidegger.

De facto, é sugerido pelo título Deriva, mas também pela valorização da errância, como forma de acesso à revelação do que está oculto, aletheia, ou seja, a descoberta da verdade do Ser. Nesta perspectiva, a errância é positiva, porque está ligada ao mistério e à abertura do Dasein, portanto representa para o homem a possibilidade de aceder ao Ser, de obter acesso ao caminho certo e de não se desviar ${ }^{11}$.

Além disso, para Heidegger, a desocultação do ser ocorre de maneira privilegiada através da arte, especialmente da palavra poética. Errância, Poesia e Arte cruzam-se no último poema de Navegações, um lugar estratégico para sintetizar e reafirmar toda a mensagem do livro.

Em suma, resulta da interpretação de Navegações que a deriva em que o homem está envolvido na busca do Ser é homóloga da errância dos navegadores e, ao mesmo tempo, da deriva da Humanidade no seu curso através da História, ou da errância do sujeito poético em busca do poema no meio do caos (cfr. Figura 2). Qualquer uma delas pode e deve produzir resultados positivos, como testemunhado pelas descobertas dos séculos XV e XVI, a partir da perspectiva desenvolvida por Sophia em Navegações. Assim, este livro propõe uma interpretação do passado e do presente e uma Utopia do Futuro.

\section{Riferimenti bibliografici}

Almeida, C. N. de. 2014. "O Feito, a Gesta e o Olhar: o Oriente nas Navegações de Sophia de Mello Breyner Andresen.” Elyra 4: 57-78.

Andresen, S. de M. B. 1967. "Hölderlin ou o lugar do poeta." Jornal do Comércio, Lisboa, 30-31/12/1967.

Andresen, S. de M. B. 1974. "Entrevista à Emissora Nacional." https://www.youtube. $\mathrm{com} / \mathrm{watch}$ ? $=\mathrm{e} 5 J \mathrm{JU} 6 \mathrm{e} 44 \mathrm{Iw} 8 \& \mathrm{t}=343 \mathrm{~s}(6 / 19)$.

Andresen, S. de M. B. 1977. “Discurso em Macau." https://pontofinalmacau.wordpress. com/2019/03/15/macau-simboliza-o-desejo-de-descobrir-e-percorrer-o-mundoate-suas-ultimas-distancias/ (9/19).

11 «The errancy in which any given segment of historical humanity must proceed for its course to be errant is essentially connected with the openness of Dasein» (Heidegger 1993, 134). 
Andresen, S. de M. B. 1980. "Luís de Camões - Ensombramentos e Descobrimentos." Cadernos de Literatura, 5: 22-9.

Andresen, S. de M. B. 1982. “Entrevista a Armanda Passos.” Jornal de Letras 16-2: 2-5.

Andresen, S. de M. B. 1983a. Navegações. Lisboa: Imprensa Nacional-Casa da Moeda.

Andresen, S. de M. B. 1983b. “Notas sobre Navegações." mais 2 poemas inéditos, Prelo 1: 107-10.

Andresen, S. de M. B. 1985. “Entrevista a M. S. Pereira.” Jornal de Letras 5-2: 2-3.

Andresen, S. de M. B. 1986. "Entrevista a E. P. Coelho.” ICALP. Revista 6, Agosto/ Dezembro: 60-77.

Andresen, S. de M. B. 1989a. “Entrevista a António Guerreiro.” Expresso 15-7: 54R-57R.

Andresen, S. de M. B. 1989b. “Entrevista a Lúcia Sigalh.” Vida Mundial: 98-103.

Andresen, S. de M. B. 1990. "Entrevista a Virgílio de Lemos.” Oceanos 4, Julho: 127-30.

Andresen, S. de M. B. 1991. "Entrevista a José Carlos de Vasconcelos.” Jornal de Letras 25-6: 8-13.

Andresen, S. de M. B. 2012. “Entrevista incluída em «Navegações».” RTP, Grandes Livros Episódio 12.

Andresen, S. de M. B. 2015. Obra Poética. Lisboa: Assírio \& Alvim.

Bíblia Sagrada. 1993. Lisboa: Edições Paulus.

Brito, J.P. 1983. "Mudança na Etnologia (Questão do Olhar).” Prelo 1: 63-72.

Ceia, C. 1996. Iniciação aos Mistérios da Poesia de Sophia de Mello Breyner Andresen. Lisboa: Vega.

Ceia, C. 2003. O Estranho Caminho de Delfos: Uma Leitura da Poesia de Sophia de Mello Breyner Andresen. Lisboa: Vega.

Chevalier, J., e A. Gheerbrant. 1989. Dictionnaire des Symboles. Paris: Robert Laffont.

Coelho, E.P. 1980. “Sophia, a lírica e a lógica.” Colóquio-Letras 57: 20-33.

Collot, M. 2011. La Pensée-Paysage. Arles: Actes-Sud.

Damásio, A. 2010. O Livro da Consciência. Lisboa: Temas \& Debates/ Círculo de Leitores.

Damásio, A. 2017. A Estranha Ordem das Coisas. Lisboa: Temas \& Debates/ Círculo de Leitores.

Deleuze, G. 2002. L'̂̂le Déserte. Paris: Éditions de Minuit.

Foucault, M. 1984. "Des espaces autres." Architecture, Mouvement, Continuité 5: octobre 46-49 https://foucault.info/documents/heterotopia/foucault.heteroTopia.fr/ $(9 / 19)$.

Guerreiro, E. 2013. "Uma perspectiva bucólica da poesia de Sophia de Mello Breyner Andresen.” Veredas 20: 55-72 https://digitalis-dsp.uc.pt/jspui/ handle/10316.2/34573 (6/19).

Heidegger, M. 1968. What Is Called Thinking. New York: Harper \& Row Publishers.

Heidegger, M. 1993. Basic Writings. New York: Harper Collins Publishers.

Heidegger, M. 2008. A Origem da Obra de Arte. Lisboa: Edições 70.

Hühn, P., e R. Sommer. 2012. "Narration in Poetry and Drama." In The living handbook of narratology, eds. P. Hühn, et al. Hamburg: Hamburg University http://www.lhn. uni-hamburg.de/article/narration-poetry-and-drama (7/19).

Labussissière, O.2014. "Littératures de l'Insularité. Une interrogation sur la portée du mythe en géographie." In L'Imaginaire Géographique. Entre Géographie, Langue et Littérature, dir. L. Dupuy L., e J.-Y. Puyo, 57-73. Pau: Presses de l’Université de Pau et des Pays de l'Adour.

Langrouva, H. 2002. "Mar-Poesia de Sophia de Mello Breyner Andresen: Poética do espaço e da viagem - I e II.” Revista Brotéria 154/155 http://www.triplov.com/ sophia/helena.html (6/19). 
Lefèbvre, H. 2000. La Production de l'Espace. Paris: Ed. Anthropos.

Lukács, G. 1971. The Theory of the Novel. Cambridge, MA: MIT Press.

Malheiro, H. 2008. O Enigma de Sophia: Da Sombra à Claridade. Lisboa: Oficina do Livro.

Martins, O. 1987. Portugal nos Mares. Lisboa: Círculo de Leitores.

Merleau-Ponty, M. 1984. O Visível e o Invisível. S. Paulo: Editora Perspectiva.

Merleau-Ponty, M. 1999. Fenomenologia da Percepção. S. Paulo: Martins Fontes.

Merleau-Ponty, M. 2018. O Olho e o Espírito. Lisboa: Nova Veja.

Nava, L.M. 2004. “As Navegações de Sophia.” In Ensaios Reunidos, 74-8. Lisboa: Assírio \& Alvim.

“Navegações 2012.” RTP, Grandes Livros, Episódio 12 https://www.youtube.com/ watch? $=x$ VIO7qytTOA (8/19).

Rocha, C. 1994. "Sophia de Mello Breyner Andresen: poesia e magia.” Colóquio-Letras 132/ 133:165-82.

Saïd, E.W. 1979. Orientalism. Knopf Doubleday Publishing Group.

Soja, E.W. 2016. Thirdspace. Malden: Blackwell Publishing.

Tally, Jr. R.T. 2018. Topophrenia. Indiana University Press.

Teilhard de Chardin, P. 1970. O Fenómeno Humano. Porto: Livraria Tavares Martins.

Toynbee, J.A. 1947. A Study of History. Abridgment, volumes I-VI, by D. C. Somerwell, New York: Oxford University Press.

Westphal, B. 2000. "Pour une approche geocritique des textes." In La Géocritique mode d'emploi.9-40. Limoges: PULIMhttps://sflgc.org/bibliotheque/westphal-bertrandpour-une-approche-geocritique-des-textes/ (6/19).

Westphal, B. 2006. “Pourquoi une Géocritique de Lisbonnne.” In Lisbonne. Géocritique d'une Ville, org. A. Montandon, Clermont-Ferrant: Presses Universitaires Blaise-Pascal.

Westphal, B. 2007. La Géocritique. Réel, Fiction, Espace. Paris: Editions de Minuit.

Westphal, B. 2011. Le Monde Plausible. Espace, Lieu, Carte. Paris: Éditions de Minuit. 